\title{
Visual and Scent as Sensory Marketing Tools in the Dental Care Services: An Experimental Research Design Approach
}

\author{
Dikta Pradika $^{a}$, Isabella Nyssa ${ }^{b}$, Primidya KM Soesilo ${ }^{{ }^{*} *}$ \\ a, b Creative Marketing Program, Management Department,BINUS Business School Master Program,Bina Nusantara \\ University,Jakarta, Indonesia 11480 \\ ${ }^{\mathrm{c}}$ Business Management \& Marketing, Management DepartmentBINUS Business School International Undergraduate Program, \\ Bina Nusantara UniversityJakarta, Indonesia 11480 \\ ${ }^{c_{*}}$ corresponding author Email: pmiranda@binus.edu
}

Article History: Received: 10 November 2020; Revised 12 January 2021 Accepted: 27 January 2021; Published online: 5 April 2021

\begin{abstract}
The objective of this research is to examine the effect of visual and scent on perceived intimacy of a service provider and consumers' dental anxiety, in the context of the healthcare industry, specifically dental clinic service. Further, this study also examined the possibility of interaction effect of visual and scent on both variables. A $2 \times 2$, full factorial, an experimental research design was conducted throughout a four-day experiment in a marketing lab of a large private university in Indonesia. The tools needed to analyse the data are SPSS data processing devices. Sampling method used in this study is nonprobability sampling - purposive sampling by making criteria to have visited a dental clinic. This research managed to collect a total of 144 samples. Findings show that visuals only have a significant effect on store intimacy and dental anxiety. Scent has no significant effect on any of the variables we study. Additionally, we found no interaction effect between visual and scent in this context.
\end{abstract}

Keywords:

\section{Introduction}

Marketing theories and practices have evolved dramatically through a series of transformations. As opposed to traditional marketing, sensory marketing considers increasingly significant estimations of social behavioral, emotional, sensory, cognitive, and symbolic nature. Sensory marketing involves consumers' senses and influences their perceptions, judgements, and behavior (Krishna, 2010). In this context, stimulants tending to all of the five senses, namely sight, auditory, smell, taste, and touch senses, attempt to impact the emotional and behavioral responses of consumers.

Certain aspects of sensory marketing have been used in the healthcare context. For instance, the use of scent from essential oils has been acknowledged in folk medicine and aromatherapy for their physiological and psychological effects (Tisserand, 1988). Dental clinics are no stranger to the use of aromatherapy. Based on the research focused on female patients, the scent of orange has been researched to have an effect of relaxation when used in dental clinics. Furthermore, orange scent provides a lower level of state anxiety, a more positive mood, and a higher level of calmness (Lehrner et al., 2000). Some dental clinics in Indonesia have been practicing the use of scent in their clinics. Several clinics around the Jakarta area have been using scent from aromatherapy in her clinic. However, there is no specification of what kind of scent of aromatherapy that shall be used (Nadya Andarani drg, Personal Communication, August 12, 2019).

While dental care is deemed as crucial to the overall health, dental anxiety has been pointed as one of the main causes of reluctance or avoidance to visit dentist or dental clinic (Armfield et al., 2006). Dental anxiety has led people with a lack of dental treatment to the worsening condition of oral health (Armfield et al., 2007). This will have an adverse impact on dental health, which may threaten the general health condition of the individual. Therefore, it is important to find ways to encourage people to visit dental clinics for check-ups by reducing dental anxiety.

Sense of intimacy may play a role in keeping the customers to come and feel at ease while they are at the clinic. Some research in sensory marketing have found that visuals affect consumers' feelings and judgements. Warm visuals have been known to be able to give the feel of warmth to the customers through the experience of imagined physical warmth. Consumers do not necessarily need an actual physical interaction to feel the sensation as the sensation can be delivered through the use of visuals such as colors. For example, people perceived red and orange colors as warm colors and blue and green colors as cold colors (e.g., Fenko, Schifferstein, \& Hekkert 
2010). Consumers who are exposed to visually warm color experience more in-store intimacy than those who are exposed to visually cold color.

Past research in sensory marketing tend to focus on individual sense. While it has brought great findings and insights, the importance of understanding the interaction between multiple senses is highly underlined by Elder et al. (2010). It is much needed to fully understand these interactions in order to know how multiple senses may affect perceived intimacy towards the dental clinic and consumers' dental anxiety. Most of the previous research in sensory marketing have focused on the retail industry. This research aims to fill the gap by investigating the roles of multiple sensory such as visual and scent in the healthcare industry.

\section{Literature Review}

Sensory marketing is a marketing sector that has been created for a couple of years and has become a significant solution to the traditional approach of mass marketing. Indeed, while marketers used to concentrate on products, acquiring customers, and operating on one-way communication, sensory marketing created the focus of experience with client therapy and multidimensional communication through digital technology (Hultén, Broweus, and Dijk, 2009). According to Krishna, sensory marketing is a marketing that involves consumers' senses and influences their perceptions, judgements, and behavior. The sensory marketing phenomenon is quite new among academics, where this sensory marketing has been applied successfully by various companies in different industries (Krishna, 2010)

Hultén et al. (2009) stated that "sensory marketing had become a synthesis of what modern culture demanded from a company and what a company could do to generate sensory experiences with the assistance of the five human senses". As per the definition given by the American Marketing Association, sensory marketing "is the marketing techniques that aim to seduce the consumer by using senses to influence the consumer's feelings and behaviors". In this context, stimulants tending to all of the five senses, namely sight, hearing, smell, taste, and touch senses, attempt to impact the emotional and behavioral tendencies of consumers.

\subsection{The Sense of Sight}

The sense of sight is viewed as the most significant sense. The vast majority trust what they can see, and they base their day by day choices on visual sensations (Møler 2003, pp. 374-376). It is frequently agreed that the sense of sight is the most prevalent of human senses. It's considered the most powerful and seductive. Sight is easily the most stimulated of five senses sensory marketing experts use.

Visual appearances can be implemented to generate brand awareness and transmit a corporate identity, according to Hultén et al (2009, p.9). This can be accomplished by submitting a unique and distinctive product or brand pictures. Visual appearance can have a major impact on quality perception (Hultén et al, 2009, p.9). Within a matter of seconds, customers can acknowledge well-designed logos and color schemes. Because sight is such a saturated feeling, today's companies need to discover a way to go beyond traditional strategies such as displays, and design.

Sight must be about offering a distinct point of view or perspective-something that forces us to realize that visual experience can be determined by businesses through physical components of the servicescape such as interior design and style, but also by intangible variables such as light and color. Applying light as such can have a huge impact on the quality of perception. This is because the different lightning intensity and placement can alter the perception of shape, color, and texture (Ching, 1996).

Warm visual has been known to be able to give the feel of warmth to the customers by giving the customers the chance to experience physical warmth. Therefore, it may affect an individual interpersonal judgement and prosocial behavior (William and Bargh, 2008). Warm and cold feelings do not necessarily need an actual physical interaction for the customer to feel the sensation. Thus, the sensation can be delivered through the use of visuals such as colors.

For example, people perceived red and orange colors as warm colors and blue and green colors as cold colors (e.g., Fenko, Schifferstein, \& Hekkert 2010). Customers that are exposed to visually warm store experienced more in-store intimacy than those who exposed to the visually cold store. Furthermore, it is proven to be applicable to use the visually designed store to influence an individual's perception of store intimacy (Baek et al., 2018).

\subsection{The Sense of Smell}

The sense of smell is heavily associated with our emotional lives. For instance, particular odors can affect the mood of a person and generate well-being (Hultén et al, 2009, p.8). Spreading scents can generate such a pleasant atmosphere that it affects the buying conduct of clients, improves the perceived value, and improves the sales volume (Isacsson et al, 2009, p. 171). In addition, odors can be used to create long-lasting memories for customers and thus faithful interactions with customers. This is because the feeling of smell is so strongly linked to memory 
that it is only possible to connect the perception of a scent that smelled before in life with previous experiences (Hultén et al, 2009, p.7). Moreover, the use of scent from essential oils has been acknowledged in folk medicine and aromatherapy for their physiological and psychological effects (Tisserand, 1988).

Based on the research focuses on female patients, the scent or odor of orange have been researched to have an effect of relaxation when used in the dental clinic. The orange scent provides a lower level of state anxiety, a more positive mood, and a higher level of calmness (Lehrner et al. 2000, pp 83-86). Even the sense of smell can be used to manipulate customers' trustworthiness and behavior. "In specific, the scents of vanilla and clementine influence the conduct of clients by unconsciously keeping them longer than they would otherwise have" (Hultén et al., 2009, p. 171). It has been affirmed in various research that olfactory upgrades improve memory and state of mind as well as may affect customers' trustworthiness and behavior.

\section{Hypotheses Development}

In the context of the retail industry, companies have spent a lot of time and resources in building and design a store. Hoping that they can get the best interaction for their customers (Baker et al., 1992). Michael Treacy and Fred Wiersema (1993) argued that customer intimacy means segmenting and targeting markets precisely and then tailoring offerings to match exactly the demands of those niches. They continued, companies that excel in customer intimacy combine detailed customer knowledge with operational flexibility so they can respond quickly to almost any needs, from customizing a product to fulfilling special requests. From the two journals, we can safely conclude that store intimacy is a marketing strategy where companies utilizing and tailoring their brick and mortar outlets to get closer and cater to their customers' needs on a personal level.

We believe while putting customers at the top of their mind dental practitioners should also be able to differentiate their business from others. Store intimacy is one way to address these kinds of issues. When we are talking about intimacy within the retail context, people are seeking experiences when they are shopping at brick and mortar stores (Thompson, 2017). The utilization of physical space to strengthen their consumer-brand connection via in-store experiences have challenged retailers strategically (Verhoef et al., 2009). Retail managers have focused on how to influence consumption behavior by arranging environmental elements such as store design and arrangement. (Bitner, 1992). Internal states (pleasure/arousal) and subsequent behavioral responses such as patronage intentions, approach intentions, and store preferences are the benefits of store atmospherics that are hyped by retail researchers (Orth \& Wirtz, 2014).

Past research on the effect of visual and scent have confirmed a significant effect on store intimacy. For example, Baek et al. (2018) found that visually warm store induced more store intimacy than visually cold store. In their research, they manipulated the independent var into warm color (represented by red and orange tone) and cool color (represented by blue). Another research by Madzharov, Block, and Morrin (2015), found that olfactory experiences such as warm scents may affect people's perception and behavior similar to that of physical warmth. Therefore, we proposed the following hypothesis:

\section{H1a: A visually warm (vs. cold) dental clinic setting will induce higher store intimacy.}

\section{H1b: A warm (vs. cold) scent in dental clinic setting will induce higher store intimacy.}

Corah, Gale, and Illig (1978) managed to yield a scale to help dental practitioners to measure the anxiety level of dental treatment patients. To dental treatment patients, dental anxiety is an important component of distress. However, different from general anxiety, dental anxiety is more specific as it is the response given by the patient to the stress specifically to the dental situation. Furthermore, it is also important for the dental practitioners to be aware of the dental anxiety level of the patient since it can help them to ease the anxiety during the procedures (Corah et al., 1978). Sohn and Ismail (2005) stated that dental anxiety is a significant determinant of whether people will regularly visit the dental clinic or not. As cited from Appukuttan (2016) that dental anxiety may come from multiple factors such as past negative or traumatic experiences, displaced learning from anxious family members or peers, neuroticism and self-consciousness, lack of understanding, exposure to frightening portrayals of dentists in the media, the coping style of the person, perception of body image, and the vulnerable position of lying back in a dental chair (Locker, Shapiro, \& Liddell, 1997; Benjamin et al., 1996; Ost and Hugdahl, 1985). Furthermore, sensory triggers such as the sight of needles and air-turbine drills, sounds of drilling and screaming, the smell of eugenol and cut dentine, and also sensations of high frequency vibrations in the dental setting can provoke anxiety (Oosterink, de Jongh, Aartman, 2008; Walsh, 2007; Hmud and Walsh, 2009)

Several studies in the past have shown the relation between dental anxiety with irregular attendance for dental care patients or total avoidance of dental care treatment (Woolgrove \& Cumberbatch, 1986; Milgrom et al., 1985). Dental anxiety is not without consequences. Having dental anxiety may lead to physiological, cognitive, and behavioral consequences (Locker, 1989). Dental anxiety is not only giving setbacks for people that are having it but also dental practitioners. Having patients that are anxious may lead to increased tension that might be able to 
compromise performance. Furthermore, it has been suggested that managing dental anxiety is one of the most difficult tasks to handle for dental practitioners (Humphris and Ling, 2000; Kent and Blinkhorn, 1991).

Past research on the effect of scent towards dental anxiety has been conducted several times. Lehrner et al. (2000), found that exposure to the scent of orange has a relaxant effect. Furthermore, they found that women that had a lower state of anxiety, a more positive mood, and a higher level of calmness are those who were exposed to the orange scent. There hasn't been a notable research on visual and dental anxiety. However, using visuals as a means to ease children's anxiety at the dental clinic has been done rather commonly. Ghadimi et al. (2018) found that presenting visual distraction by playing cartoons seems to be effective in reducing anxiety on children especially during dental treatment under local anesthesia. Based on that, we would like to propose these hypotheses:

\section{H2a: A visually warm (vs. cold) dental clinic setting will lower dental anxiety}

\section{H2b: A warm (vs. cold) scent in dental clinic setting will lower dental anxiety}

In addition to the proposed hypotheses, we would like to also see if there is an interaction effect of visual and scent on store intimacy and dental anxiety. Past research on the visual and scent have confirmed that there is a positive interaction with one another. For instance, odors can modulate visual perception and performance in visual tasks, particularly by influencing the saliency of visual objects during attentional blink (Robinson et al.. 2013). Another research shows that the interaction between visual and olfactory, in the context of sweet products, can further enhance the sweetness of perception and sucrose solutions. They try to show the figurative image while enhancing the sweetness rating more than the non-figurative image. (Belien et al, 2011). Based on past studies on visuals and theories, we can conclude that in sensory marketing, there is an interaction between visual and olfactory. However, we are not in the position to hypothesize the direction of the effect. Thus, we would like to propose this hypothesis:

\section{H3a: There is an interaction effect of visual and scent on store intimacy}

\section{H3b: There is an interaction effect of visual and scent on dental anxiety}

\section{Method}

To test our hypotheses, we used an experimental study with a 2 (visual: warm vs. cold) $\times 2$ (scent: warm vs. cold), full factorial, between-subjects design with random assignment to any of the four conditions. Data collection was run for 4 consecutive days in a marketing lab of a large private university. Sampling method used in this study is nonprobability sampling - purposive sampling by making criteria to have visited a dental clinic.

\subsection{Data Collection Method}

During the four-day experiment we directly approach students and staff by asking them to become our respondent for our design project. After they agreed to join us, we led them to the marketing lab. We separate our sessions to multiple batches a day for one condition. One batch or group consists of 1 to 6 people.

First, we introduced ourselves and explained to them that they were going to see two images. Thus, we showed them the image of the waiting room and practice room in order and asked them to imagine as if they were inside those two rooms. However, we turned the lights off in order to make them fully focused on the images. After showing them the images, we asked them to scan the QR code on the scene that will direct them to a link that will direct them to the questionnaire. The questionnaire was written in English, but most of the proceedings were instructed in Bahasa Indonesia. However, there were cases where we had international students or English speaking students so we had to conduct the proceedings in English. Meanwhile, while they were answering the questionnaire given to them via the link from QR code, we loop the two images so that they can see and imagine clearly. After they were done with the questionnaire, we revealed that what they just did was a part of a sensory marketing experiment and brief them about our research. Lastly, we give them souvenirs in the form of snacks and a bottle of mineral water.

\subsection{Design and participants}

We set up the marketing lab with different conditions each day. We managed to collect 47 respondents during the first day, 35 respondents during the second day, 32 respondents during the third day, and 30 respondents during the last day. As we have stated before, for an experiment, we need to have at least 30 respondents per group or condition in order for it to have the answers that may represent a population or having the equivalent of representing $80 \%$ of the population following.

One hundred forty four respondents were randomly assigned to any of the 4 conditions. On day 1,47 respondents were recruited, followed by 35, 32, and 30 in the following days, consecutively. Profile of respondents is presented in the following table: 
Table 4.1 Profile of respondents

\begin{tabular}{|c|c|c|c|}
\hline \multicolumn{2}{|l|}{ Characteristics } & \multirow{2}{*}{$\begin{array}{l}\text { Number of respondents } \\
69\end{array}$} & \multirow{2}{*}{$\begin{array}{l}\text { Percentage } \\
47,90 \%\end{array}$} \\
\hline & Female & & \\
\hline Gonuta & Male & 75 & $52,10 \%$ \\
\hline \multirow{4}{*}{ Age } & $<20$ & 75 & $52,10 \%$ \\
\hline & $>30$ & 5 & $3,50 \%$ \\
\hline & $21-25$ & 42 & $29,20 \%$ \\
\hline & $25-30$ & 22 & $15,30 \%$ \\
\hline \multirow{2}{*}{ Occupation } & Employee & 34 & $23,60 \%$ \\
\hline & Student & 110 & $76,40 \%$ \\
\hline \multirow{2}{*}{$\begin{array}{l}\text { Do you visit } \\
\text { dental clinic } \\
\text { regularly? }\end{array}$} & No & 92 & $63,90 \%$ \\
\hline & Yes & 52 & $36,10 \%$ \\
\hline \multicolumn{2}{|c|}{ Total number of respondents } & 144 & \\
\hline
\end{tabular}

\subsection{Procedures}

The procedure in this experiment is that first of all respondents were placed into four (4) conditions, namely: warm visual with warm scent condition, warm visual with cool scent condition, cool visual with warm scent condition, and cool visual with cool scent condition. Our experiment adopted two experiments from the past research from Baek et al. (2018) for the visual experiment and Madzharov et al. (2015) for the olfactory experiment. We conducted them simultaneously.

For the visual experiment we adapted the experiment conducted by Baek et al. (2018). Where we created two videos for visual models of a dental clinic that represent warm and cold visuals respectively. We asked our respondents to imagine themselves being in the store that we presented to them through the aforementioned visual representations.

Meanwhile, for the olfactory experiment, we adopted a pilot study conducted by Madzharov et al. (2015) where they ran the study using cinnamon scent to represent warm scent and peppermint scent to represent cool scent. We were using a marketing lab located in a large private university where the participants filled out the survey in groups. Furthermore, similar to Madzharov et al. (2015), we set an electric diffuser within the rooms to emit ambient scent into the room for at least 10-15 minutes before the session began. After being exposed to both the visual and scent stimuli in the experiment process, the respondent answered questions subsequently.

\subsection{Measures}

Measures of the dependent variables were adapted from Baek et al. (2018). Perceived intimacy variable was measured using 2-item, 5-point semantic differential that responded to question such as: "How do you perceive the dental clinic to be?" (e.g. not intimate - intimate; not close - close). Dental anxiety was measured using a 5items, 5-point semantic differential scale that responded to question such as: "How do you feel now?" (e.g. not anxious - extremely anxious).

\section{Result}

\subsection{Manipulations checks}

A manipulation check was run to ensure that the manipulation procedure worked well. There are four experiment conditions in this research: (D1) Cold visual (Cold Condition) paired with cold scent (Cold 
Condition); (D2) Cold visual (Cold Condition) paired with warm scent (Warm Condition); (D3) warm visual (Warm Condition) paired with cold scent (Cold Condition); (D4) Warm visual (Warm Condition) paired with warm scent (Warm Condition).

Tabel 4.3 Manipulation Check

\begin{tabular}{|l|l|l|l|}
\hline Condition & Cold & Warm & Total \\
\hline Cold Visual & $\begin{array}{l}100 \% \\
(79 \text { people })\end{array}$ & $0 \%)$ & $\begin{array}{l}100 \% \\
(79 \text { people })\end{array}$ \\
\hline Warm Visual & $0 \%)$ & $\begin{array}{l}100 \% \\
(65 \text { people })\end{array}$ & $\begin{array}{l}100 \% \\
(65 \text { people })\end{array}$ \\
\hline Cold Scent & $\begin{array}{l}100 \% \\
(82 \text { people })\end{array}$ & $0 \%)$ & $\begin{array}{l}100 \% \\
(82 \text { people })\end{array}$ \\
\hline Warm Scent & $0 \%)$ & $\begin{array}{l}100 \% \\
(62 \text { people })\end{array}$ & $\begin{array}{l}100 \% \\
(62 \text { people })\end{array}$ \\
\hline
\end{tabular}

Table 4.3 shows the result of manipulation check that $100 \%$ of the respondents for each visual and scent managed to classify the correct visuals into what we have expected. All seventy-nine people (100\%) perceived a blue-white color dominant visual as a cold visual, 65 people $(100 \%)$ perceived a red-orange color dominant visual as a warm visual, 82 people $(100 \%)$ recognized peppermint odor as a cold scent, and 62 people (100\%) recognized cinnamon odor as a warm scent.

\subsection{Perceived Intimacy}

To test hypothesis $1 \mathrm{a}$ and $1 \mathrm{~b}$, the dependent variable was submitted to two-way ANOVA. The two-way ANOVA analysis showed that there was a significant main effect of visual $(F(1,140)=11.565, p<0.01)$ but no significant effect was found for scent $(F(1,140)=2.693, p=0.103$,$) on the intimate level felt by consumers in a$ case dental clinic. Also, no significant interaction effect was found between visual and scent on store intimacy $(\mathrm{F}$ $(1,140)=0.571, p=0.451)$, as shown in Figure 1 below. Therefore, H1a is accepted; while H1b is rejected. From all conditions, it can be seen that the level of intimacy occurs when the visual condition is warm vs. scent warm $\left(M_{\text {cold }}=3,929\right.$ vs. $\left.M_{\text {warm }}=4,637\right)$. These results indicate the direction of the effect in accordance with the H3a research hypothesis rejected for the dependent variable store intimacy.

\section{Store Intimacy}

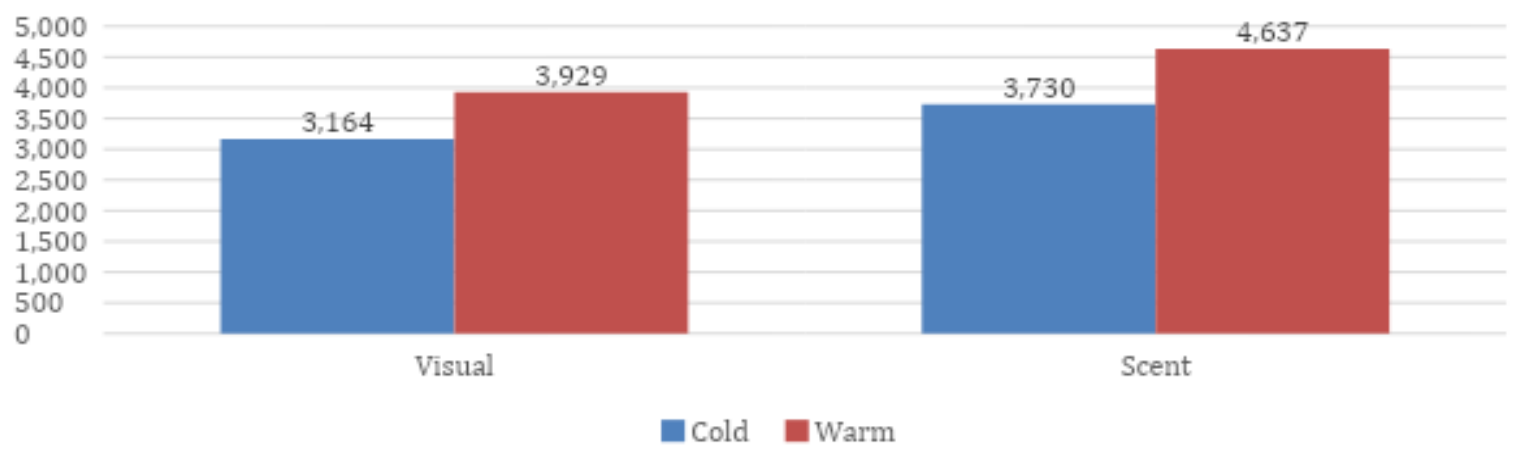

Figure 1. Main Effect on Perceived Intimacy

The result shown is in line with research conducted by Baek et al. (2018) that a visually warm store design can be used as a method to influence customer's perception of store intimacy. While Baek et al. (2018) study relates to retail setting, our research focuses on the use of the same method in designing an intimate and close dental clinic setting. Unsurprisingly, the similar result also happened in the dental care industry. Compared to the cold visual, warm visual can make customers or patients feel intimate in the waiting room and practice room. Furthermore, it also applies to feeling close with the clinic. Apparently the warm visual is able to make customers feel the warmth of the room despite not directly situated in the actual dental clinic. The study does further confirm the use of colors and surface materials in a design to project intimacy and closeness of a store or place to customers, especially in the case of the dental care industry. 
The result is not able to fully support the previous study, where Madzharov, Block, and Morrin (2015) found that olfactory experiences such as warm scents may affect people's perception and behaviour similar to that of physical warmth. However, the store intimacy when the room is scented with warm scent still induces higher store intimacy compared to cold scent although it is insignificant.

\subsection{Dental Anxiety}

To test hypothesis $2 \mathrm{a}$ and $2 \mathrm{~b}$, the dependent variable was submitted to two-way ANOVA. The two-way ANOVA analysis showed that there was a significant main effect of visual $(\mathrm{F}(1,140)=22.828, \mathrm{p}<0.01)$ but no significant effect was found for scent $(F(1,140)=0.004, p=0.951$,$) on the anxiety level felt by consumers in a$ case dental clinic. Therefore, $\mathrm{H} 2 \mathrm{a}$ is accepted; while $\mathrm{H} 2 \mathrm{~b}$ is rejected. Furthermore, there was no significant interaction effect between visual and scent on dental anxiety $(F(1,140)=2.418, p=0.122)$, as shown in Figure 2 below. From all conditions, it can be seen that the level of anxiety occurs when the condition is visually warm vs. scent warm $\left(M_{\text {cold }}=1,481\right.$ vs. $\left.M_{\text {warm }}=2,199\right)$. These results indicate the direction of the effect in accordance with the hypothesis of the $\mathrm{H} 3 \mathrm{~b}$ study rejected for the dependent variable dental anxiety.

\section{Dental Anxiety}

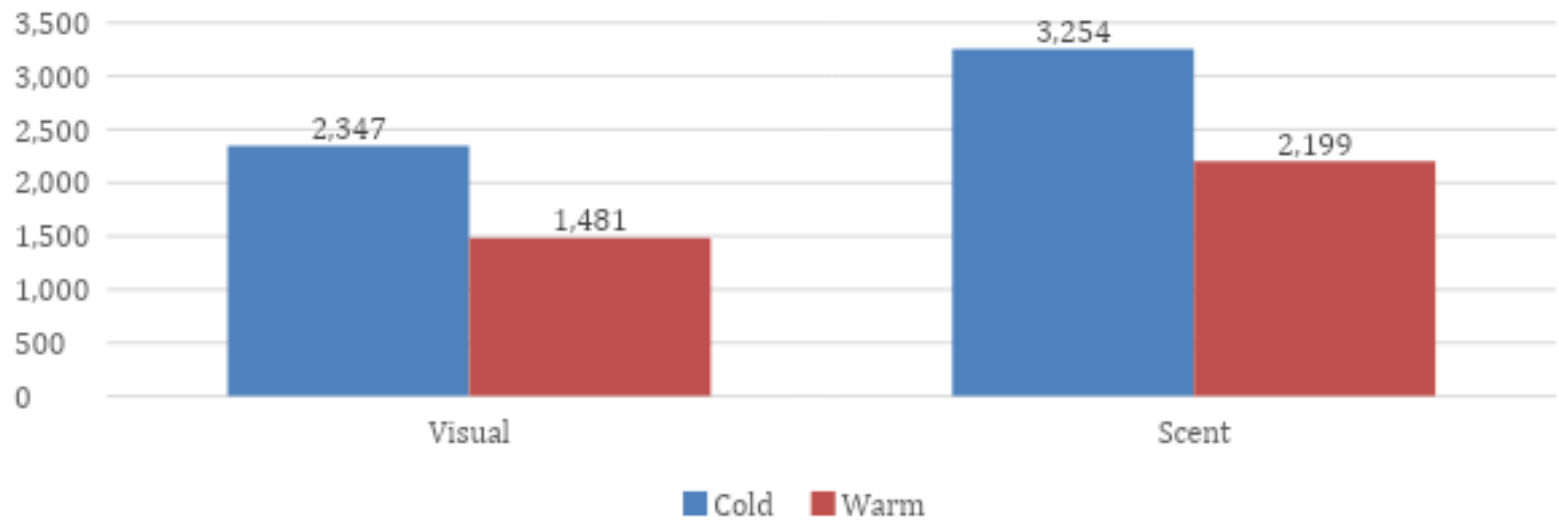

Figure 2. Dental Anxiety Effect

Based on the result, visual significantly affects dental anxiety, in that, when the visual of the clinic is perceived to be warm, respondents' anxiety is lesser than when the visual is perceived to be cold. Thus, this means when a visual design of a dental clinic using warm colors and surface materials is able to ease customer or patient's dental anxiety. The statement also supported by the estimated marginal means on the effect of visual (warm vs. cold) on dental anxiety, that shows that dental clinics can ease their customers or patients dental anxiety by using a warm visual design in their dental clinics. The result is supported by their previous research related to the use of visual and anxiety by Ghadimi et al. (2018) where they found that presenting visual distraction by playing cartoons seems to be effective in reducing anxiety in children especially during dental treatment under local anaesthesia. This shows that the utilization of visual is indeed able to reduce customer or patient dental anxiety.

The estimated marginal means of scent towards dental anxiety for both warm and cold scent is insignificant. However, both means are still on the lower side of the scale. The study by Lehrner et al. (2000) where the study found that exposure to the scent of orange has a relaxant effect. Furthermore, they found that women that had a lower state of anxiety, a more positive mood, and a higher level of calmness are those who were exposed to orange scent. However, the study did not indicate whether orange is a cool scent or warm scent. This can lead to the fact that the previous study was comparing conditions when a dental clinic is scented and not scented. Meanwhile, when we were comparing conditions where both rooms are scented, the results may show insignificance between the scented rooms.

\section{Discussion}

The research method used in this research is by experimentation to see the effect of two sensory variables on consumers' responses. In this study, with the context of healthcare, especially dental clinics, it can be seen from the results of the analysis above that only visuals have a significant effect on store intimacy and dental anxiety; but no scent. This can be seen from the results of the analysis based on experiments that have been carried out for four days. Based on the experimental results, store intimacy increases when the visual is set to warm conditions. On the contrary, a cool visual condition triggers a feeling of less intimacy toward the clinic. Similarly, dental anxiety will decrease when the visual of the clinic is set to warm conditions; while anxiety increases as respondents are exposed to cool visual conditions. 
The experimental research results confirm that scent does not have significant influences on store intimacy, dental anxiety. Therefore, this study fails to confirm the power of scent in influencing customers' responses toward dental clinic consumption experience. In addition, there is no interaction effect of visual and scent on store intimacy, dental anxiety. This means that the most effective way to influence customers' response toward dental clinics would be by utilizing the visual aspect.

There might be several factors that contributed to the results being this way is. one of them being that this study is fairly limited on the diversity of the respondents. Most of them are students from a large private university in Indonesia and they are all from the same generation which is Gen Y. Another possible reason is that in order to have more significant results is to have the experiment conducted in a real dental clinic complete with all the ambience that enhances the situation better.

Our research shows that sensory marketing can be used as a strategy to influence consumers' responses in various industries, including the healthcare industry, such as the dental care industry. In dental care, dental anxiety is a crucial element that may contribute to consumers' willingness to visit the dental clinic. Implementing the use of warm visuals would help dental practitioners to ease their patients' dental anxiety. Despite the non-significant statistical effect of scent on dental anxiety, differences in reaction are still found. Therefore, dental clinic practitioners can still utilize the use of scent to decrease the anxiety level. The use of warm visuals and enhancing it with warm scent would help dental clinics to attract more patients to come and visit the clinic that may boost the number of people who are willing to overcome their anxiety to visit dental clinics.

The use of warm visuals would also help players in the dental care industry to do more experimenting with their patients' intimacy in mind. This research shows that dental clinics may focus more on the use of warm visuals in their advertising. The use of warm visuals can also be used in how dental clinics market themselves in the public to attract potential customers, through the use of pictures and photos on their social media platforms. This is especially true in today's environment that is characterized heavily by consumers' dependency on social media in searching information. As the result of our research suggested that the use of visuals can be effective to induce store intimacy and reduce dental anxiety especially among young generations. The implementation of warm visual may also be used, not only limited to the scope of the dental clinic industry, but also to the healthcare industry as a whole.

\section{Limitation and Future Research}

Several limitations exist in this research that may affect the results of this study. First, in this study, we only focused on two sensory aspects: visual and scent as independent variables, and customer intimacy and dental anxiety as dependent variables. Obviously, there are other variables that may have effects as well but are not included in this study.

The majority of respondents from this study were under the age of 20 years old. Therefore, the results may be different if done by focusing on segmentation based on age and generation between generation $\mathrm{X}$, generation $\mathrm{Y}$ and generation $\mathrm{Z}$ with various experiences to the dental clinic. Due to the possibility of differences in perspective and experience as well as understanding in the sensory marketing concept. Our respondents are those who have visited the dentist or dental clinic at least once in their lives. Therefore, it would be great to invite respondents that had visited the dentist in the past 6-8 months. The number of respondents in this study was also limited to 144 people. While the sample size conforms with the experiment rules, it would be better if more respondents are added so that results would be more corroborated.

In this case the researcher wants to provide suggestions for further research in order to develop research on the same topic, namely in sensory marketing. In addition to developing the scope and number of respondents, further research can also add more aspects of sensory marketing variables studied in addition to the variables that have been studied in this study such as audio, touch and taste. With the addition of other variables from various aspects from marketing may lead to deeper findings. Furthermore, more variables may help to find whether there is an interaction effect between variables. This research was held in a room in a building with limited access and limitations. Thus, further research may conduct an experiment that may represent a situation in a dental clinic setting better. Conducting the experiment in a real setting in a real dental clinic may also help to achieve a better and deeper understanding of sensory marketing in the dental clinic service. A more focused research on a certain population may help dental clinics to be able to pick its target market as it can be more focused.

Further research may experiment in other healthcare service industries such as but not limited to hospital, clinic, apothecary, and beauty clinic. It is hoped that in future studies more extensive research can obtain more accurate information 


\section{References}

Appukuttan, D. P. (2016, March 10). Strategies to manage patients with dental anxiety and dental phobia: Literature review. Clinical, Cosmetic and Investigational Dentistry. Dove Medical Press Ltd. https://doi.org/10.2147/CCIDE.S63626.

Armfield, J. M., Spencer, A. J., \& Stewart, J. F. (2006). Dental fear in Australia: Who's afraid of the dentist? Australian Dental Journal, 51(1), 78-85. https://doi.org/10.1111/j.1834-7819.2006.tb00405.x.

Armfield, J. M., Stewart, J. F., \& Spencer, A. J. (2007). The vicious cycle of dental fear: Exploring the interplay between oral health, service utilization and dental fear. BMC Oral Health, 7. https://doi.org/10.1186/14726831-7-1.

Baek, E., Choo, H. J., \& Lee, S. H. (Mark). (2018). Using warmth as the visual design of a store: Intimacy, relational needs, and approach intentions. Journal of Business Research, 88, 91-101. https://doi.org/10.1016/j.jbusres.2018.03.013.

Baker, J., Levy, M., \& Grewal, D. (1992). An Experimental Approach to Making Retail Store Environment Decisions. Journal of Retailing, 68(Winter), 445-60.

Bitner, M. J. (1992). Servicescapes: The Impact of Physical Surroundings on Customers and Employees. Journal of Marketing, 56(2), 57-71. https://doi.org/10.1177/002224299205600205.

Ching, F., 1996. Architecture: Form, Space, and Order. Van Nostrand, New York.

Corah, N. L., Gale, E. N., \& Illig, S. J. (1978). Assessment of a dental anxiety scale. Journal of the American Dental Association (1939), 97(5), 816-819. https://doi.org/10.14219/jada.archive.1978.0394.

Elder, R. S., Aydinoglu, N. Z., Barger, V., Caldara, C., Chun, H., Lee, C. J., ... Stamatogiannakis, A. (2011). A Sense of Things to Come Future Research Directions in Sensory Marketing. In Sensory Marketing: Research on the Sensuality of Products (pp. 361-376). Taylor and Francis. https://doi.org/10.4324/9780203892060.

Fenko, A., Schifferstein, H. N. J., \& Hekkert, P. (2010). Shifts in sensory dominance between various stages of user-product interactions. Applied Ergonomics, 41(1), 34-40. https://doi.org/10.1016/j.apergo.2009.03.007.

Ghadimi, S., Estaki, Z., Rahbar, P., \& Shamshiri, A. R. (2018). Effect of visual distraction on children's anxiety during dental treatment: a crossover randomized clinical trial. European Archives of Paediatric Dentistry, 19(4), 239-244. https://doi.org/10.1007/s40368-018-0352-x.

Hmud, R., \& Walsh, L. (2009). Ansiedad dental: causas, complicaciones y métodos de manejo. Journal of Minimum Intervention in Dentistry, 2(1), 237-248. Retrieved from http://micompendium.org/journal/index.php/JMID/article/view/123.

Hultén, B., Broweus, N., \& van Dijk, M. (2009). Sensory marketing. Sensory Marketing (pp. 1-183). Palgrave Macmillan. https://doi.org/10.1057/9780230237049.

Humphris, G., \& Ling, M. S. (2000). Behavioural sciences for dentistry (1st ed., pp. 71-85). Edinburgh: Churchill Livingstone.

Isacsson, A., Alakoski, L., \& Bäck, A. (2009). Using multiple senses in tourism marketing: The Helsinki expert, Eckerö Line and Linnanmäki amusement park cases. Tourismos, 4(3), 167-184.

Kent, G., \& Blinkhorn, A. S. (1991). The psychology of dental care (pp. 1-28). Bristol: Butterworth-Heinemann. https://doi.org/10.1016/C2013-0-04492-1.

Krishna, A. (2011). Sensory marketing: Research on the sensuality of products. Sensory Marketing: Research on the Sensuality of Products (pp. 1-396). Taylor and Francis. https://doi.org/10.4324/9780203892060.

Krishna, A., Elder, R. S., \& Caldara, C. (2010). Feminine to smell but masculine to touch? Multisensory congruence and its effect on the aesthetic experience. Journal of Consumer Psychology, 20(4), 410-418. https://doi.org/10.1016/j.jcps.2010.06.010.

Lehrner, J., Eckersberger, C., Walla, P., Pötsch, G., \& Deecke, L. (2000). Ambient odor of orange in a dental office reduces anxiety and improves mood in female patients. Physiology and Behavior, 71(1-2), 83-86. https://doi.org/10.1016/S0031-9384(00)00308-5.

Madzharov, A. V., Block, L. G., \& Morrin, M. (2015). The cool scent of power: Effects of ambient scent on consumer preferences and choice behavior. Journal of Marketing, 79(1), 83-96. https://doi.org/10.1509/jm.13.0263.

Ministry of Health Republic of Indonesia (2018). Rokok: Akar Masalah Jantung Dan Melukai Hati Keluarga. Retrieved August 15, 2019, from http://www.depkes.go.id/article/print/18052800008/rokok-akar-masalahjantung-dan-melukai-hati-keluarga.html

Milgrom, P., Fiset, L., Melnick, S., \& Weinstein, P. (1988). The prevalence and practice management consequences of dental fear in a major US city. Journal of the American Dental Association (1939), 116(6), 641-647. https://doi.org/10.14219/jada.archive.1988.0030.

Møller, A. R. (2003). 6. In Sensory systems: Anatomy and physiology (pp. 374-376). Amsterdam: Academic Press. https://doi.org/10.1016/B978-0-12-504257-4.X5000-6. 
.Oosterink, F. M. D., De Jongh, A., \& Aartman, I. H. A. (2008). What are people afraid of during dental treatment? Anxiety-provoking capacity of 67 stimuli characteristic of the dental setting. European Journal of Oral Sciences, 116(1), 44-51. https://doi.org/10.1111/j.1600-0722.2007.00500.x.

Orth, U. R., \& Wirtz, J. (2014). Consumer Processing of Interior Service Environments: The Interplay Among Visual Complexity, Processing Fluency, and Attractiveness. Journal of Service Research, 17(3), $296-309$. https://doi.org/10.1177/1094670514529606.

Sohn, W., \& Ismail, A. I. (2005). Regular dental visits and dental anxiety in an adult dentate population. Journal of the American Dental Association, 136(1), 58-66. https://doi.org/10.14219/jada.archive.2005.0027.

Thompson, D. (2017). What in the world is causing the retail meltdown of 2017. The Atlantic. Retrieved August 15, 2019 from https://www.theatlantic.com/business/archive/2017/04/retail-meltdown-of-2017/522384/.

Treacy, M., \& Wiersema, F., (1993) Customer Intimacy and Other Value Disciplines - hbr.org. Retrieved August 15, 2019 from https://hbr.org/1993/01/customer-intimacy-and-other-value-disciplines

Walsh, Laurence. (2007). Anxiety prevention: Implementing the $4 \mathrm{~S}$ principle in conservative dentistry. Auxilliary. 17.

Woolgrove, J., \& Cumberbatch, G. (1986). Dental anxiety and regularity of dental attendance. Journal of Dentistry, 14(5), 209-213. https://doi.org/10.1016/0300-5712(86)90003-5 